\title{
II. 解ttteiluwgen.
}

\section{Die XXVII. Derjammlung Deuticher forfmänner $\mathfrak{3} \mathfrak{\text { Schwerin. }}$}

Sont Forftmeifter (ே)

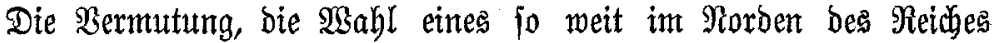
gelegenen Drtes wie Sdberin fönne ben Bejuch ber Berjammlung beutjoher Forftmänner ungünftig beeinfluffen, hat fich nicht bemabrbeitet.

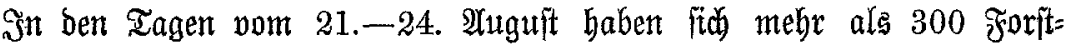
leute aus allen Gatuen ber beutiden \&ande zut erniter QYrbeit zujammen= gefunden und bas, was die gaftlidbe Stabt, fowie bas hohe Şerridjerbaus uns bot, mürzte bas Dajein, erhöhte bas $\mathfrak{B b h l b e h a g e n . ~}$

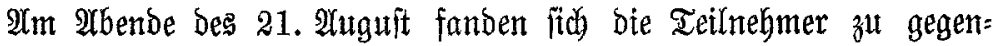

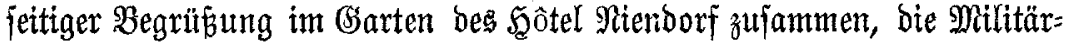
mulif fonzertierte. Daas war eine Frende, ein Şänbejçütteln, angeregte

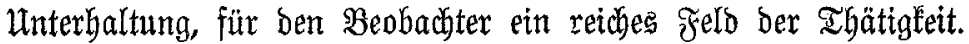

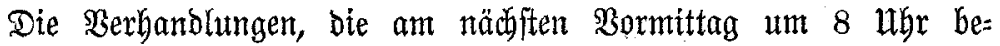
gamen, fanden im feftlid gefdymüdten Saale ber Tonthalle ftatt. Der "verlappte" Esang, ber zal biejent leitete, zeigte, dẩ wir uns im Ranbe

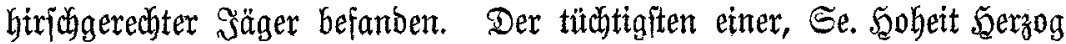

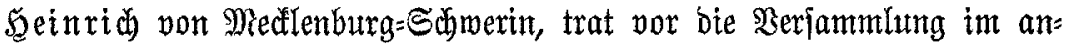

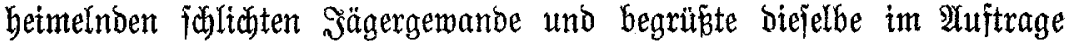

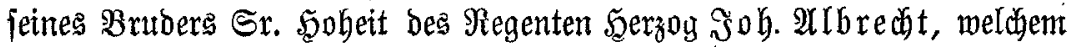
es unmöglich war, jelbit zu erjoheinen. Dem herzlichen $\mathfrak{B i l l f o m m e n t ~ f u ̈ g t e ~}$

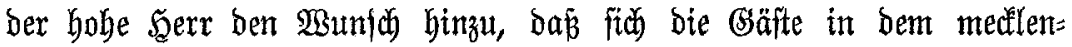
burgifiben sanbe woblfüblen möbten.

Dhexforitmeifter Schirmadier von \$reslau eröffnete barauf in $\mathfrak{A b}=$ wejenheit bes vorjäbrigen erjten ßräfitbenten bie XXVII. Beriammlung Deuticher Foritmänner uno erteilte bem Landforitmeifter von $\mathfrak{B} e r g$ aus

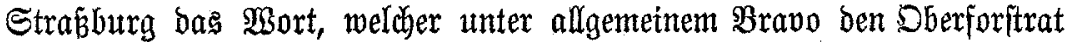

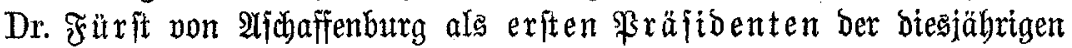
Berjammlung in Borjhlag brachte, als zweiten Den grof̉berzogl. Dber= jägermeifter unb Dberlanbforftmeifter von $\mathfrak{M}$ onroy=Sdyerin.

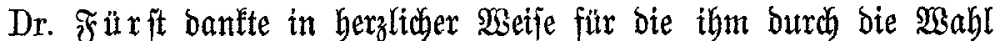
zut teil gemorbene (shre, bie aber nidjt ihm allein, fonbern bauptjädblich bem Süben des Reibles burch feine ßerjon erwiejen worben jet.

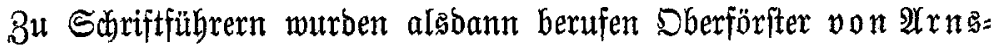

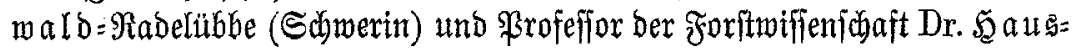
rath $=$ Siarlanthe. 


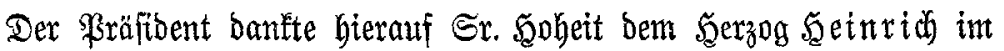

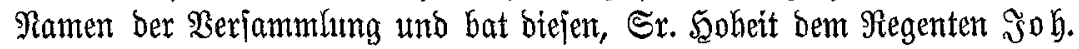

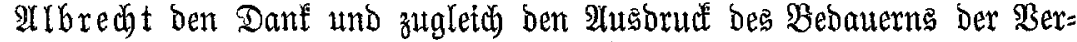

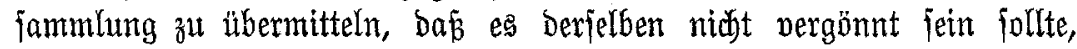

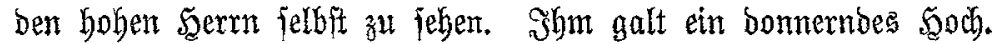

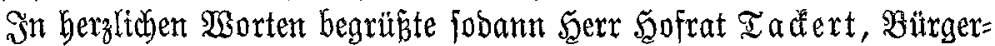
meifter ber Stad Schmerin, im Ramen bes Magiftrats bie \$erjantmlung uno banthe bafür, bán fie ber Einlabung gejolgt jet. Die Berbältnifie

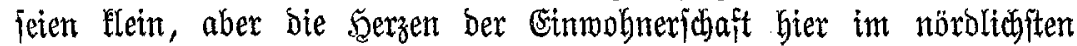
Deutibland falügen nicht meniger marm, als in anderen Deilen bes Reiches. Rach entiprechendem Dant jeitens des Präftbenten, fowie einigen gefdüftliden Mitteilungen burd Dberforftmeiftex von Müller, bie auf

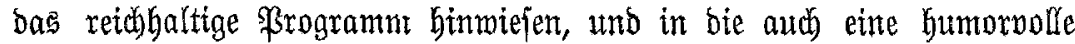
Strafrebe veridlungen war gegen jene, weldhe ibre Anmelbungen ver= Ipätet hatten, murde eine Depefde des Schmeizer Forftnereins vertejen,

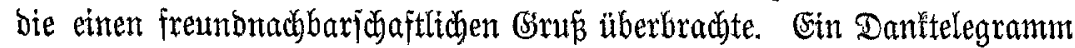
fam zur $2 \mathfrak{l b j e n b u n g . ~}$

Nummehr fonnte an bie geftellten 2 ufgaben berangetreten werben, uno Dberforftrat Dr. Fatrit fprach bie Erwartung aus, Das bie Şerband=

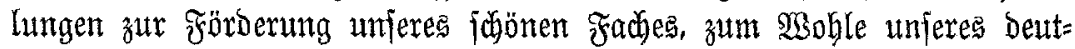

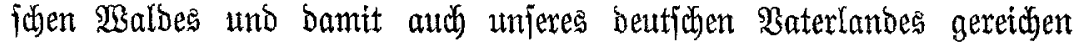

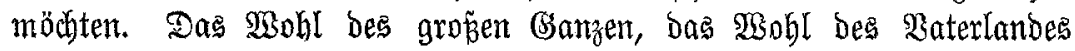
jolle uns leiten, bann folgten wir bent Sime unjeres erhabenten Ratjers,

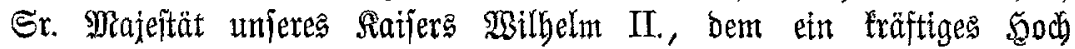
exichallte.

3u Ihema I erfielt ber Referent $\mathfrak{P r o j}$. Dr. von sorey= Tübingen bas Mort.

Das Thema I lautet: Sit die von ber XXVI. গ̉erjammlung

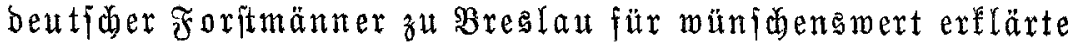
Berjomelanng ber Berjammlung beatjor for fortmäner mit

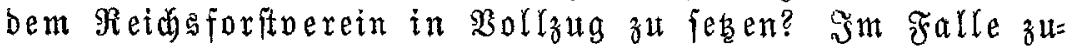
ftimmenden Bejwluffes - SBexatung des burb bie in Breglau gewählte Rommiffion oorgelegten Sagungentwarfes und şeichluffafiung hiermegen.

(s) joll hier nicht näber auf Das Thema eingegangen werben, metl

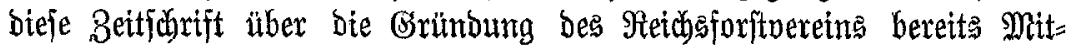
teifungen gebradbt hat. ${ }^{1}$ )

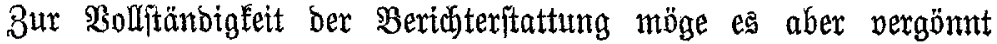

1) Sergl. Sanuarbeft bes Forftw. Gentr. SIattes 1900. 


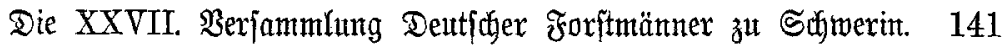

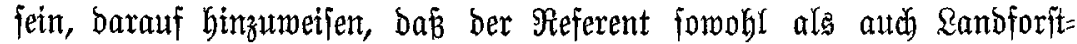
meifter Dr. Dandelmann, Dberjoritmeifter Rey, Dberforitrat von Raebfeld (München), Ranbesforftrat Duaet $=\mathfrak{F a g l e m}$ (Samnover) und anbere warm für bie Sache eintraten.

Sn lehter Stumbe batte ber füritlich Gohenzolleriade Foritmeifter

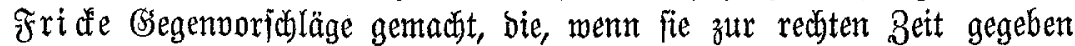
worben wären, gewi manchen Freund gemonnen baben würben. Itber jo hatte Rambforftuteifter Dr. Dancéclmann redjt, went er bem äujerft

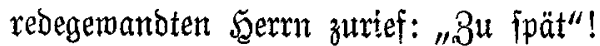

(Einftinmig faft wurbe bann aud beichloffen: Der beutidje Fronft= verein ift gegritndet und erbält biejentge Srganifation, weldbe bie pon ber Somniiffion geftellten Sab̧ungen angeóen. Für bie Sorftandswahl galt folgender $\mathfrak{B o r}$ idjlag:

Eriter Fräfțent: Lanbforĩtmeifter Dr. Dand el mann, Ebersmalde,

3weiter "Dberporitmeifter $\mathfrak{R} \mathfrak{y}$, Meb.

Dritter " Gräflicher Forftmeifter $\Re$ tebel, Mughau.

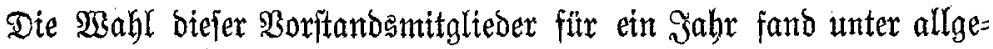
meiner 3uftimmung ftatt.

Thema II: Sit die in Dänemark gebräuchlide Art der Budenbeftandespflege bisher in Deutfdland foron zur alt =

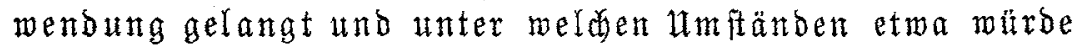
fich ibre esinführung in beutjon Balbungen empjeblen?

Das Referat war in bie Şand bes in ben leşten sahren fo bäufig genannten Forftaffefiors Dr. Mesger von Münoen gelegt und bie B্be= jüätsleitung hat fich Daburch ben vollen Dant ber Serjammlung errungen. Landforitmeifter Dr. Dandelmann jagte mit pollem Rechte

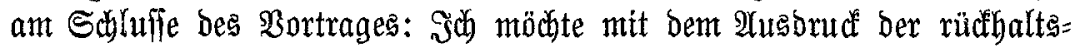
lojeften, wärmitten $\mathfrak{A}$ nerfennung beginnert für bie heroorrageno=tüdhtige 2rrbeit und für bie $\mathfrak{B}$ orarbeit, bie Dr. Mekger geliefert uno geleiftet

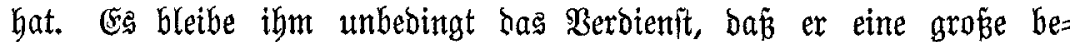
beutungşvolle Frage angeregt habe, bte er uthe unter bem 2 Uufwano aller

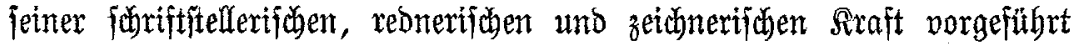
habe, wie es bis jetst bei ben beutichen Foritnerjammlungen noch nicht gejwehen jei. Soldbe $\mathfrak{B g}$ orte ate biejem Munde vor einer offiziellen $\mathfrak{B e r}=$

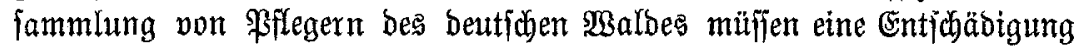
jein für bie vielen $\mathfrak{A n f e i n d u n g e n ~ u n d ~ f u ̈ r ~ m a n c h e s ~ f o ̈ h a r f e ~ M o r t , ~ d a s ~}$ Forftafjeffor Dr. Megeger in lekster Beit zu hören befam.

Doch wenden wir ung nach biejem furzen 2 Ibjodpeifen zur Sache. Dr. Megger leitete jeinent $\mathfrak{B a r t r a g}$ ein burd ben Şinmeis barauf, 


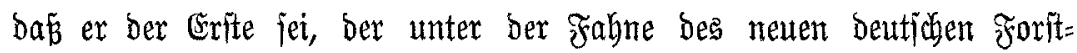
vereing bie Shyre bätte zu beribten.

Das Thema ftelle bie Buthen= "Beftandespflege" zur Dishuftion, bieje begriffe aber nidbt allein bie Durdjoritungen, jonbern er müffe auth auf andere Maß́regeln Ginweifen uno giebt

I. $B^{\mathfrak{u} r}$ Drientierung eine Einteilung zu ben Mápregeln ber Beitandespflege. Rebstere jei zmeifach:

Die eine 2 rt biene bažl, bie 3umadisthätigleit bes Beftandes

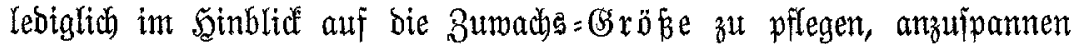
uno vor Beeinträdtigungen zu bemahren, obne baf fie zugletid erziche= rif h, formgebend auf bie Sindivibuten einmirte.

Şierher zäblt Dr. Megager bie \$Bilbung fleinter arbteilungen, weldhe

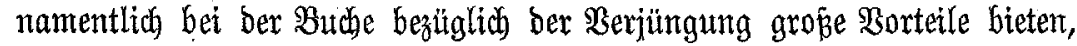
indem fajt jebe Mait ausgemubst werben lömne.

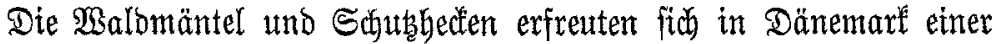
gröferen 2 Uasbildung als bei uns - weil fie bas Sltma, jowie ber untaufgörlicbe austrocknenbe Wind forberten.

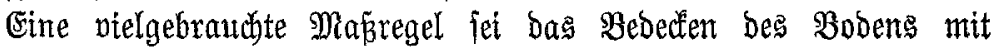

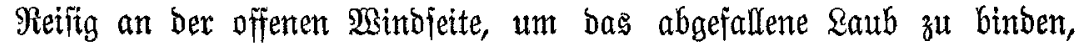
wenn ber Boben nicht mebr fo iit, wie er jein jollte.

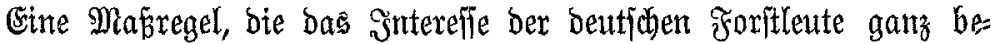

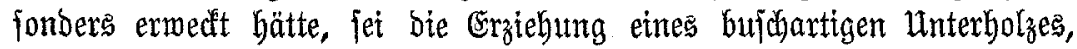

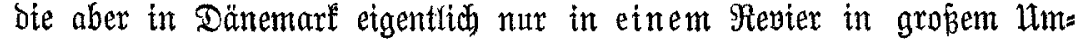
fang augageilbt würbe, bort aber aud in gan worzüglicher 2 Beife. Es

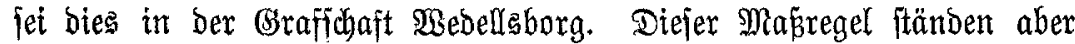
bie bänijchen forfitleute nibgt fo inmpathifd gegenüber, wie viele beutjose es thut, indent fie fagten, man fönne bas wohl in ber erften Syälfte bes seitandeslebens, im lebten Teil ber Umtriebszeit aber liep̉e fith ber

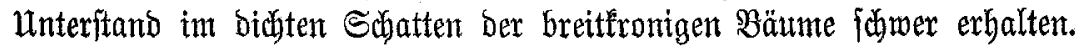
Bejonders witnjwenswert jei bas Borhandenjein einer Flora von fraut= artigen Sdbattempflanzen, aus biejen kömne man auf geeigneten \$oben=

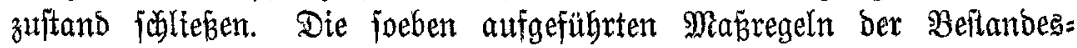
pflege gipfelten in ber Errbaltung und F̋̈rberung ber $\mathfrak{B o b e n t b a ̈ t i g f e i t , ~}$ woburch die Bitloung jener Şumugform geföroert merbe, melche bas

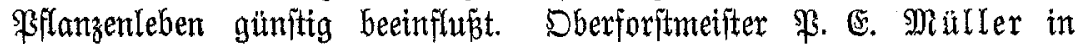
Sopenhagen nentt bas bie Mullbiloung, welche er in jeinem treff= lichen $\mathfrak{B e r k e}$ "Stubien über bie natürlidjen Sumusbilbungen" (F̌. Springer, Berlin, 1887) in vorzüglichjter Weife jojildere. Şn Dänenart molle man Keine zujammentängende, Iangjam verwejende Laubbedfe, jonbern eine jolde, bie fich fabon in sanf eines Sabres der Satptjache nad zer= 


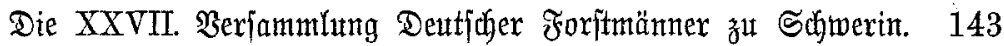

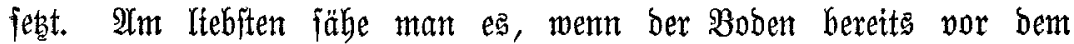

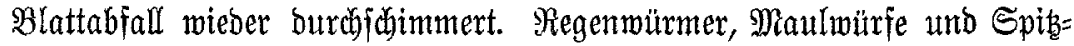
mäuje förberten bie Berfebung, es jei bas jene Bobenfauna, welche Miuller bireft verantmortlich mache für bie Rrümeliftruttur (Mull=

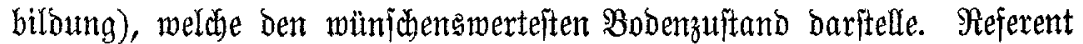

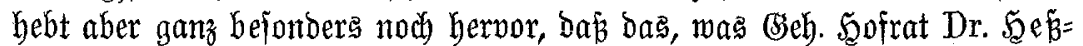
rateben in dem neu aujgelegten Maldbau von Sever als Mullboben bezeidinet, etwas ganz anderes jet.

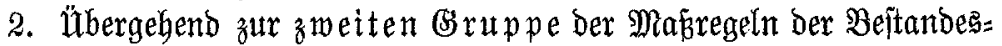
pflege, alfo auf biejentgent, weldye in erfter sinie anf bie sinzelglieber bes Beftandes erzieberifø, formgebend einmirfen, hebt Rejerent vor allem bie Durdjoritungen, alsbann Freibiebe und aidtungshiebe bervor.

Dieje Mákregeln jeien etwas ganz anderes, als bie unter 1 ge= nannten, bei ihnen hanole es fich um die Ronzentrierung bes Butwadjes

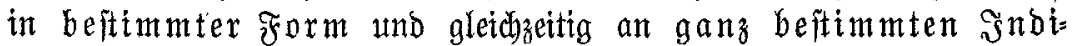
viouen voer Stammlaffen. Wha Durd bie Rronenplege weroe ber 8uwachs geföroert. Die zweite Bruppe der Makregelt - bie Durdy= foritungen - Yönnten aber nur bam von burdijichlagendem Eriolg fein, wenn wir neben ber Rronenpflege für einen guten Bobenzujtand forgten,

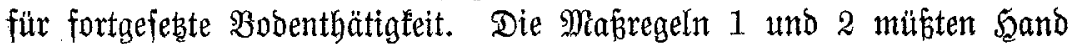
in Şand gehen, lekstere follten im Gegenfak zu erfteren bie Mapregelln Der Beftandes= = Erziehung genannt werben.

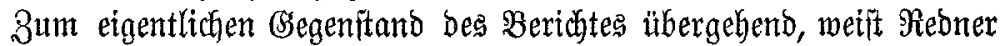
zunäbdit Darauf hin, auf was ee bei ber bänifdhen Durchforftung ant= fomme, Denn nur baun fönne ein Bergleid gezogen und über bie Ein= führung bebattiert werben. Şn äurerit anfchaulicher \$Beije hatte Dr.

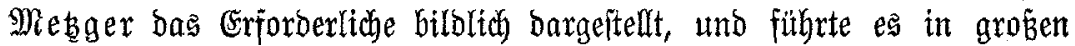
$\mathfrak{I a f e l n}$ vor.

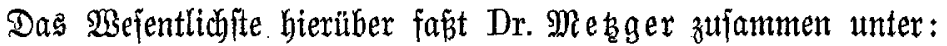

II. Eigentümlidbeiten ber in bänijden Buddenmälbern üblichen Durdforfing

Dieje Eigentümlidatetten werben in 3 Şauptteile getrennt. Sie finden ihre Begritndung in:

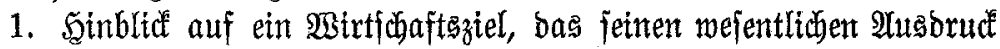

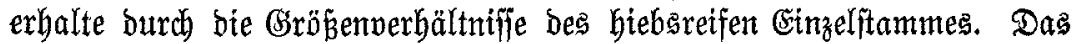

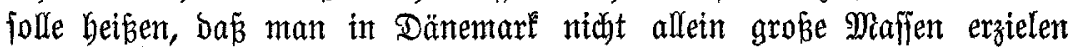
will, fonoern man lege aud barauf $\mathfrak{B e r t , ~ b a j ~ b i e ~ b i e b s r e i f e ~ M a f f e ~ a u t s ~}$ einer wemn auch geringeren $8 \mathfrak{a} \mathfrak{h l}$ Dafür aber ftarǩer Stänme beiteht.

Şn ber erften \$älffte ber Utmtriebszet würben bie befferen Stämme 
ausgejuht, welde man zum Teil mit D̈lringen bezeidne. Man molle aber fein Schema aufftellen, fondern lajpe von Fall zu Fall Berfobiebungen

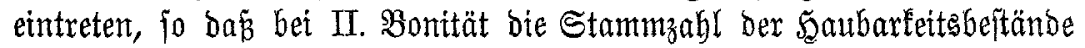
zmijhen 180 und 200 ichwante. Die geringeren Bonitäten bätten bet gleidjem 2Ulter felbitneritänolich eine größzere Stammzafl.

WBent aber nux bie beften Stämme ben Mrbtriebsbeitano bilden

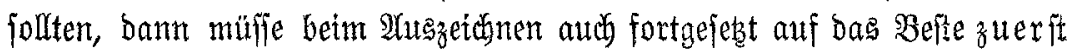

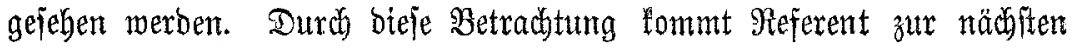
(Sigentümlitufetet, nämlitus:

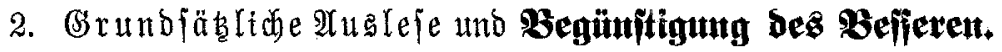
Bishyer bätte man in Deutibland in ber Regel beim 2 Uuszeldinen ber Durchforftungen zuerfit auf bie fiblecht gejormten und abfömmlicten Stümme gejehen. Dảs gejobäbe in Dänemark nicht, bort gelte als erfte Frage: SBas muin für bte befferen unb beften Slämmte gethan merben? Darauf erjt folge bie Frage: Sind joblecht geformte ober im

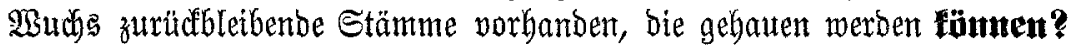

Seine fobon in ben bänifchen Reijebildern Lundgegebene 2luffaffung bes exiteu unb widt liert Dr. Mebger wie folgt:

Diejentgen Stämme jind vor allen anderen zu fällen, bie einen ober gar mehrere an Shaft unb Rrone beffer ge= ratene Radbarn an bem zu erhaltenden und weiter a

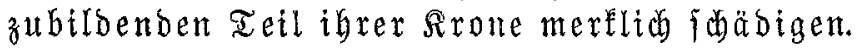

Sm 3. 2lbjak, welcher lautet:

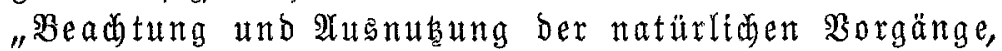
weldye fich bei ber Entmickelung bes Einzelftammes im Beitande abjpielen"

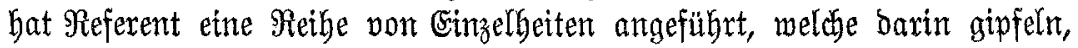
bás man mur bann mit Erfoldg arbeiten fönne, menn man bie Ratur

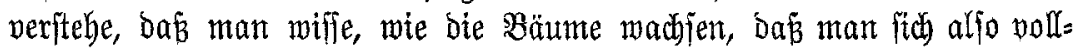
ftändig flar merben fann, wie man verfahren numb, um bas seftectite Biel zu erreidjen.

Snbbejondere ift bie Beaditung folgender Thatjachen herworgehoben worben:

a) Nur eine gute Beriüngung gemäbrleiftet einen rajoben und

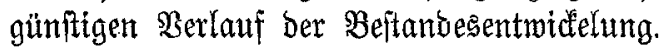

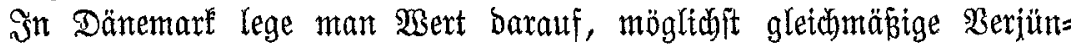
gungen zu befonmen, bann betrabte man bort vom Samenjahr an bie

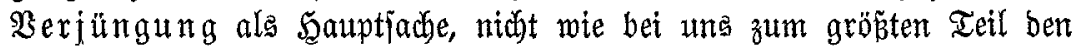
Ridutungsazumachs, ben habe man bort fợn vorber gehabt, Deshalb räıme naan bort fo fornell als mögltid und juche bahin zu wirten, baj ber 
Die XXVII. Berfammlung Deutfiber Foritmäntex zut Schwerin. 145

junge Stamm rajch in bie Şähe wächit, um bie Beit, welche Roften

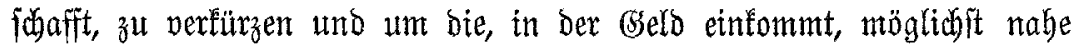
zut rialdent.

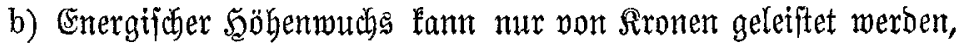

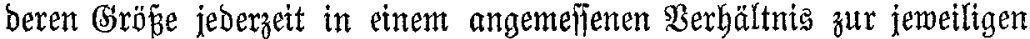
Grnö̉e bes ganzen Baumes fteht.

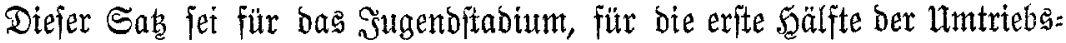
zeit uno für bie Shaftbildung von gang bedentender Widjtiglett uno

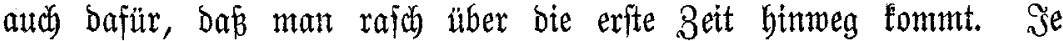

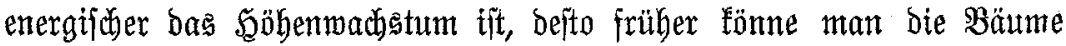

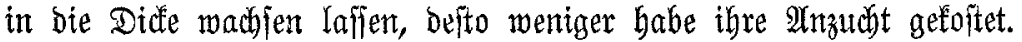

Unter bem angemeffenen Serbältniffe verftehe man in Dänemarf, Dá̉ bie Srone nicht meniger wie $1 / 3$ ber ganzen Schaftlänge beträgt, etwa 0,4. Dort jage man, Bäıme mit fletnen Sronen fönnten nidbt jo fräftig wadjen, wie joldhe mit groben. Der Däne burdforfte, bamit bie Reinigung nicht zu energifón fortjchreite.

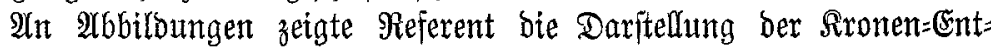

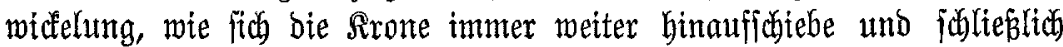
bis zur Şaubarfeit die gleiche Söbe bebalte. YItch bie eingeflemmten

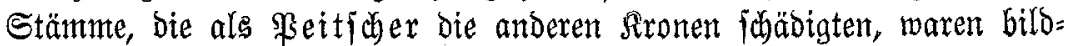
(iid) bargeitellt; biejen geböre bie 2 (rt.

c) Einte vollommene, burdjlaufende Schaftaxe wirb nur von

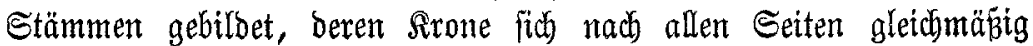
entmickeln $\mathfrak{f a n n}$.

Sine Ralamität, ber wir bei ber sermextunty ber alten Butchen= beftänbe, weldje felten durdhforftet feien, immer begegnen, fei bie 3 wi ejel= bilbung. Sin Baum, ber fith nad) allen Seiten bin gleictimäätg ent= mičeln Yönne, habe verbältnismäpig viel weniger Bẻelegenheit Bwiejel zut bilden, als ber im engiten Salub empormadjende. Snt Mittelwald habe man viel wentiger 3wiejel als in Şochwald. Wenn zwei Bäume zat nabe bei einanoer ftänoen und nadh einer Seite gepeitidit mürben, nach ber anderen Seite aber eine befier entmicfelte firone hätten, jet es bod

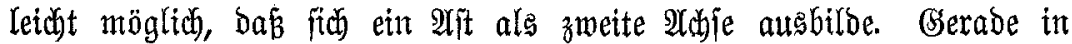
ber S̈ngend gejdähe bas viel, und wenn man anjangs jebe (sinjettigfeit vermetoe, erbalte man aucil wentger 3roiejel.

d) Die Schaftreinigung geht am letdhteften von ftatten, menn bie Steilftelling der siffte gewahrt wirb.

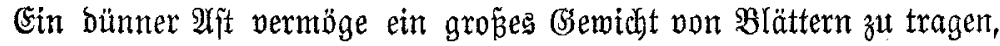
wenn er fteil ftebe. Solle aber eist 2 ift leidjt abgejtopen werben, was

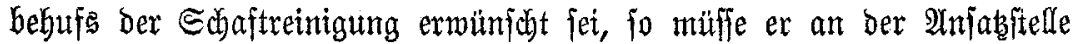


bünn jein und bas jeien bie fteil geffellten ärfte. Bäume, bie Ǧelegen= beit bätten, fich fohon frübzeitig in bie Breite zut legen, reinigten fing fobledbt. Deshalb jolle man butroh geeigneten Schlużgrab auf Steilitellung ber Sifje hinarbeiten unb baz̆ jeten ganz bejonders bie Rebentiämme erforberlich.

e) Die Sdaftreinigung fodreitet am energifojiten und nadbal= tìgiten fort bei Ronlurrenz gleidjentwid́celter Stämme.

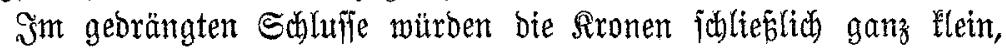

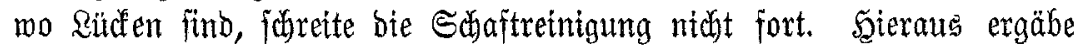
fir.h, baz man Stämme von gleicher Entwidfelung nicht in zu groper $3 a \mathfrak{b l}$

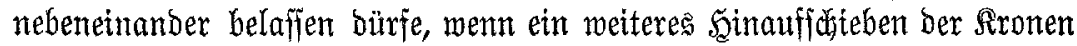

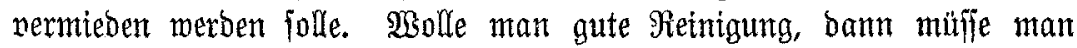
gleich entwidfelte Stänme zujammenbringen.

f) Wadtsraum=Ermeiterungen werben raf d mur von Rronen mit gerabe ausgerectiten ilften ausgemust, und zwar burch Senfung ber

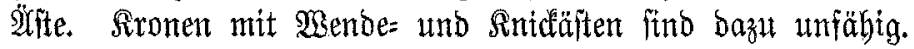

Diejer Sab gelte für bie żeite Šälffte ber Ummtriebszat. Maut wolle in Dänemarl, baj, wenn ber Sronemantą bis zur gemünibten

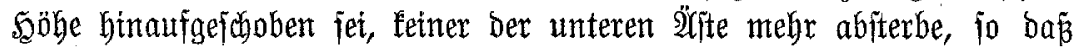

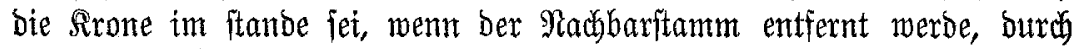
Senten ber sifite ben gebotenen alftraum rafid auşumbsen.

g) bie nadbarlidhen Bez̧iehungen Der Stämmte unter einander veränbern fïb in ber sugend raich, mit zunehmenbem arter immer langfamer.

Das fet ber Brumb, weshalb bie Dänen in jungen Beetäntben alle 3 Sahre, Dann alle 4 Sabre 2 . Durchforfteten (wollen! b. Ber.) Sie burchforiten aljo in ber sintgend oft und foblieblich in alten Beftänben nur etwa alle 10 ฐahre. Die Zahl Der Durdforftungshiebe, bie währeno ber ganzen Umtriebszeit üblich jei, weiche aus biefem Grunde faum ab von ber unjerigen, wenn wir wie üblich mit 5 jährigen Şnterwallen rechneten, wả ja gemöhnlid bei ben Ertragstafeln ber Fall fei.

In ben inftruftiven Tafeln zeigte alsbann ber $\Re$ Referent bie Ent= widelung eines Beitandes nom etma 30. Jahre bis zu bem Beitpunft, zut weldyem fich bie Fronen voll entwickelt baben und itch gegenjeitig fibäbigen.

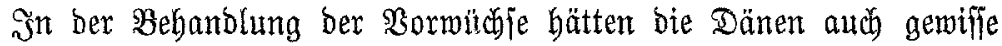

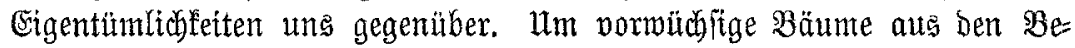
ftänden mit möglichjt wentg Schaben für ben Saauptbeftand herauts= zunehmen, würoen biejelben burdh Ringeln zum 2lbiterben gebradbt. Die

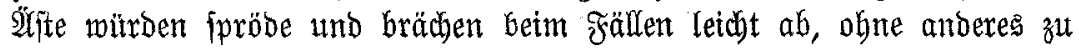




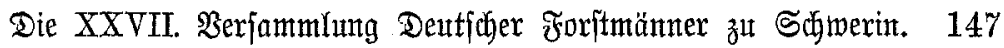

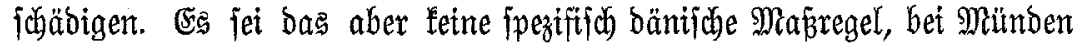
geichähe bas in vielen Revieren mit gutem Errolg.

Den Salub ber Iafeln bildete die Wiebergabe eines 62 jäbrigen Budjenbeftandes, ber bis zut $15 \mathrm{~m}$ binauf gereinigt ift und man bätte ber Wirtichafter bejhloffen, bie Bäนme bes Albtriebsbeitandes auszunählen es jeien etwa 200 Stämme auf 1 ha in gleichmäp̈iger $\mathfrak{S e r t e i l u n g . ~}$

Sin einem ber burch Beidonumg bargeftellten Beftände, ber noch in Gohem Mliter eine jebr groß̉e Stammzahl aufameifen bätte, feien alle möglident Formen von Stämmen vertreten.

Şּ foldhen Beftänoen müffe man jehr langjam vorgehen, benn wo menig gute Stämme jeien, fönne man nidbt regelmää̉g burchforiten.

Ein weiterer Seitfat lautet:

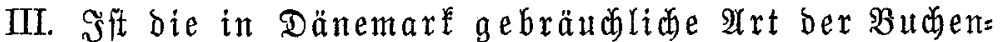
beftandespflege bisher in Deutioland jon zur Arombung gelangt?

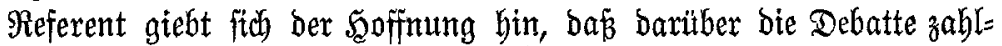
reidge $2 \mathfrak{n}$ fichten zum $\mathfrak{2}$ usbutud bringe und giebt von jeinen Erfahrungen bas Folgende fund:

1. Sn vollem $\mathfrak{M m}$ mange wohl nicht - abgejeben won eintigen

Revieren in Sdylesmig=holitein vor 1864 - teilweije ja.

Sugenoburchforittungen werbe man wohl am jeltenften nach biejer

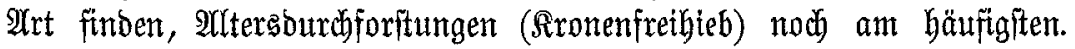

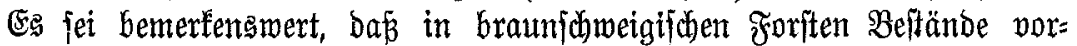
fommen, weldhe ben bänijichen fehr ähnlid finto.

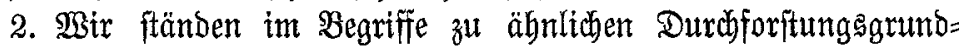
jäken überzugehen.

Sn ber Praxis jei man bie und ba foujon ein gutes Stüd voran= geeilt. Es Dürje beshalb an ber 3eit jein, endlid aud bie veralteten theoretijchen Brundlagen ber Durchforitungslebre fallen zu laffen und von Grumb auf neu zu bauen.

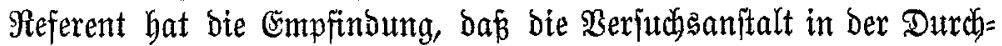
forftunggifrage nodh ben gleidyen Stanopunlt verträte, wie früher. WBtx mübten uns vor allem zum (Grundfake machen: Begünftigung bes Bejieren.

IV. Hnter melden Umftänben etwa würbe fid ibre ềin= führung in beutjoch $\mathfrak{B a l}$ aungen empfehlen?

Referent giebt auf bieje leb̧te Frage nachjtehenbe 2 Intwort:

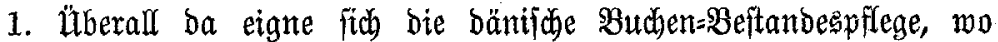

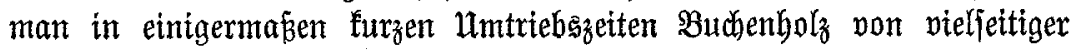
Serwendbarfeit erzieben molle. 
2. Die unmittelbare 2lmwenoung fet nur möglid bet jungen Beftänoen von einigermá̧en guter sejchaffenheit.

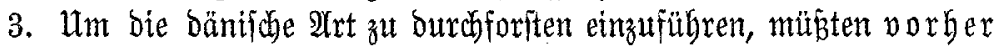
andere Bebingungen erfült werben ober Modifilationen eintreten, näntich:

bei abrormen Bobenz̆uttänton,

bei itarter Ungleibhyeit Der Stammentwicfelung in Den Beitänoen,

bei ftarker Einzelmijăung mit anderen Şolzarten,

bet Mangel an guten Rronen (Eichenfreihieb) in ben älteren Beftändent tnd

in Bindlagen.

8um Schluffe fagt bér Beriobterflatter, er habe fich bemilht, bet ber

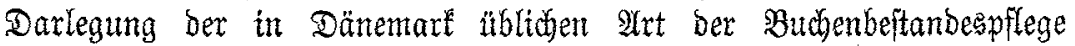
vom Buten bas Befte heraugzugreifen. Nidht überall in Dänemarl werbe bas gezeichnete Sobeal erreidyt. Man jolle aber ein sobeal haben, Itm ïberbaupt etwas erreichen zu lönnen, wir follten eine präztje $\mathfrak{B o r}=$

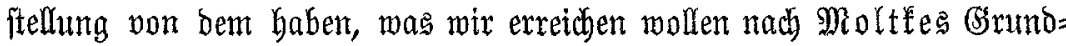
fake: erft wägen, bann wagen.

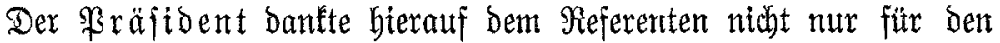

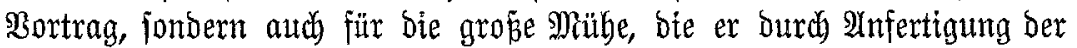
Tafeln gebabt bätte und weift auf ben reichen Beifall bin, welcher be=

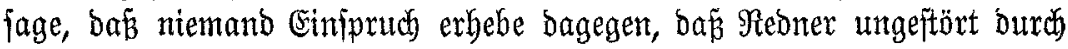
die Fräfibentenglocke über bie erlaubte Beit gejprochen babe. Sodann wirb bie Distuffion eröffnet und es betritt zunäabt bie Rebnertribüne Foritmeifter Frömbling=(Sold hen:

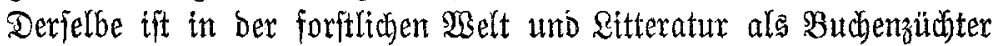

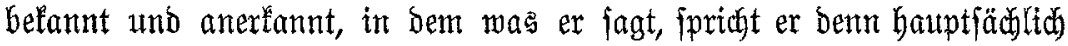
aud über bie Frage ber \$1uchenverjüngung, ntcht von ber Durdfforfung

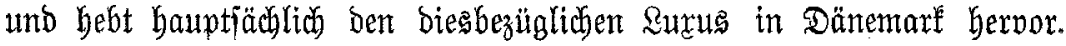

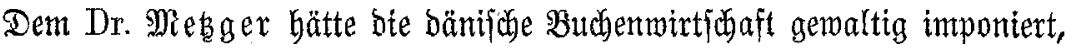
er babe ftch burd ben fremben Glant ein wentg blenden laffen und jebe

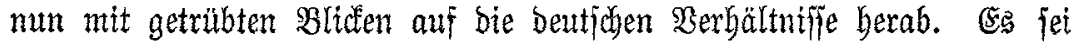
fobon vor Meser von einer Menge nambafter beutifher For fitbeamten bie

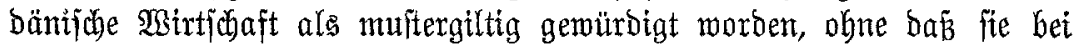

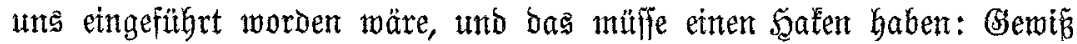

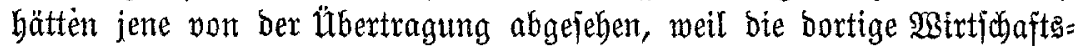

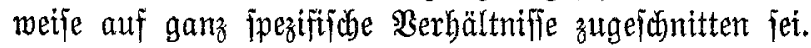

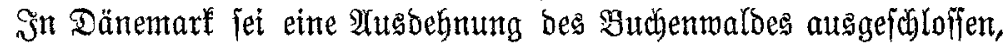

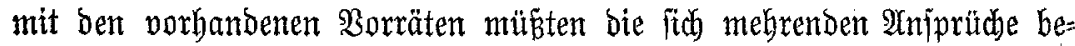
friebtgt werden. $\mathfrak{B e n n}$ aud Dänemart burd bie günftige $\mathfrak{a} a g e$ ber Sdyiffahrt Gelegenbeit biete, fehlento Produfte einguführen, fo jet bas 


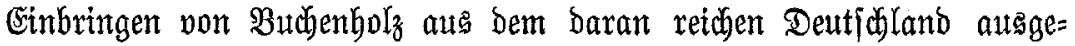
johloffen, weil bei unts bie Iransportfojten bis zur See zu boke find.

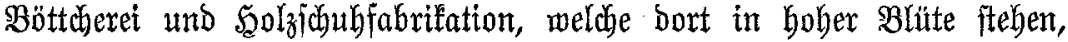
jpielen bei uns eine Durdbaus untergenronete Rolle. Dänemarf beêthe gar leine Mineralťble, bas Brennholz fei badurd gut vertäuffich. Die

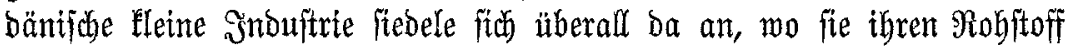

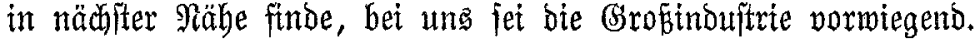

2Bir in Deutfidlano hätten ein retches (Erbe an Butchenmalo über=

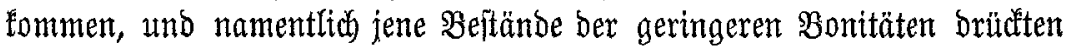

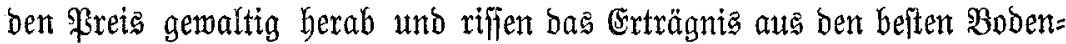
flaffen mit fich: Wair brauchten beshalb nicht auf eine Bermehrung ber Buchenbeitänoe Sebaddt zu nebmen, wie bas in Dänemarf ber Fall fet. Durch Dieje Berbältniffe ertläre es fich, baj bie beutiche Buthenwirijchaft gegen bie bänijbe extenfin genannt werben muk, weabalb wir uns rajch von Den geringmertigen Biuchenbeitäntoen frei maden mürşter.

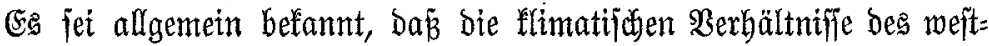

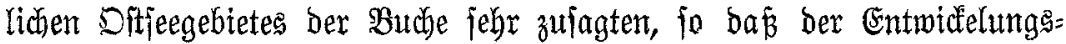
gang bier ein viel rajojerer jei als fonftwo und zu Mafjenerträgen uno

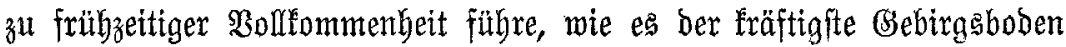
nitht biete.

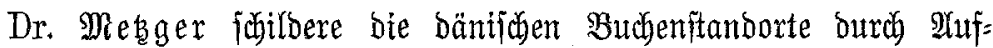
zählung ber ber beiten Sumusform zujagenden charafterpflanzen; es jei

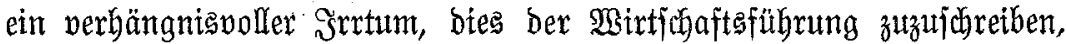

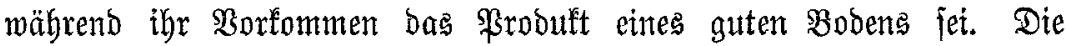

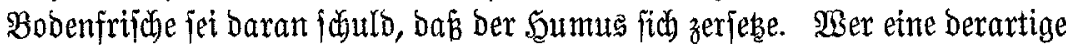
Bobenfrifiche habe, befinde fich in Der glürflidiften Rage, er fönme letwt verjüngen, er fömne burchforiten, wie er molle, ja er fönne faum etwas

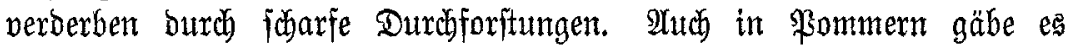
ähnliche Stanborte mie in Dänemart und Reoner verfichert alts eigener

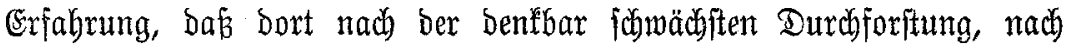
altbeutjher WBeije, jofort eine eble Flora ben Boben bede, beren $\mathfrak{U r t e n}=$ reidhtum biejenige in Dänemarł utbertreffe. Ebenjo irrtümlid ericheine

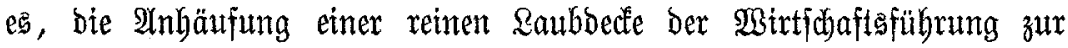

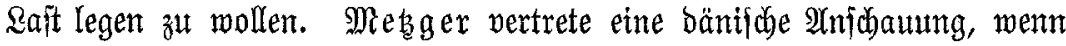

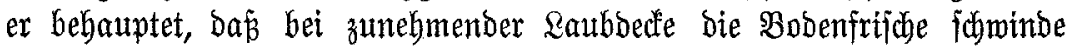

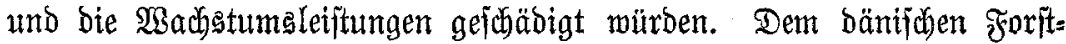
wirte jeten wejentlich andere uno vorteillaftere Wrirtidaftsbebingungen gegeben als ung, bie beutfichen Foritleute bätlen fich mit mannigfaltigeren Berhältniffen vertraut gemadht, für unt gelte ber (Grundjak, baß̧ eine

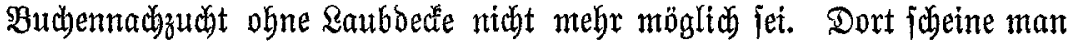


nicht zu wiffen, was Streuberedtigungen bedeuten, uno meld foäbliche

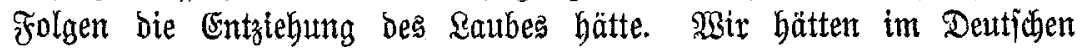
Baterlande weit mebr joblechte Bodenverhältniffe für bie Buche als günitige

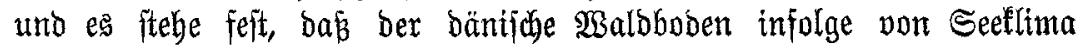
fruct)tbarer fei, als ex es bei ung ift. Es müffe ferner geleugnet werben,

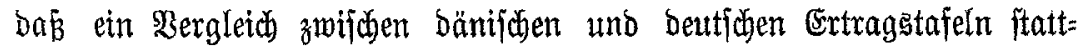
finden fönne. Die in ben Reijebilbern gegebenen Beipiele feien nicht pitchaltig. Entiprecheno rid,tige Bilber erfielten wir, wenn z. B. bie

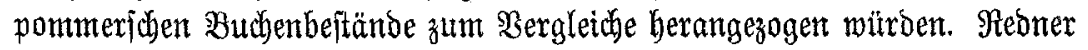

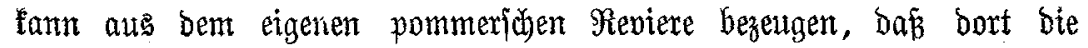
Maj̄enerträge, namentlich audb biejentgen ber Bornumumgen, ben bänijian

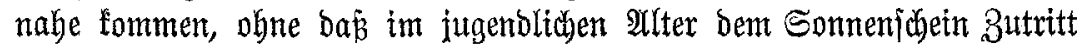
zum Boden gegeben werbe.

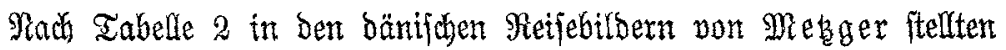
fich bie Mafien bes Arbtriebsbeftandes bei beutjober und bänijober Beftandes= pflege gleib), bod habe lebtere ftärfere Stammourchmeffer, erftere hingegen

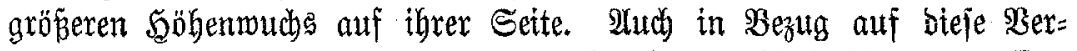
Gältniffie jei ber Bergleitch Mebger's anfechtbar, es bleibe bie Frage offen, meldber Beftand mit gleicher Mafje Der mertwollere jei.

(Unterbredsung burch Den \$räftoenten, welcher barauf aufmertian

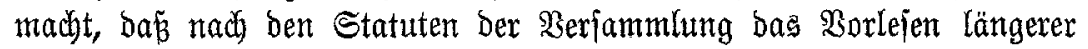

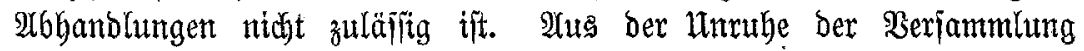

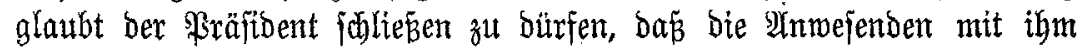
übereinftimmten, wem er bäte, frei zu iprecher. - Bravo!)

Forftmeifter Frömbling fäbrt fort:

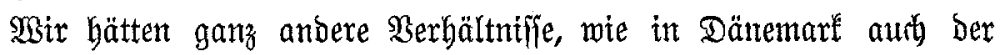

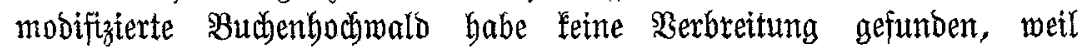
er Für bas groß̧e Ganze nidht geeignet jei. SBei feiner geringen Stantm=

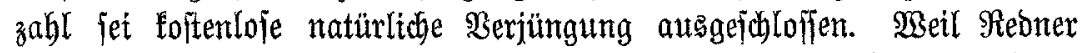

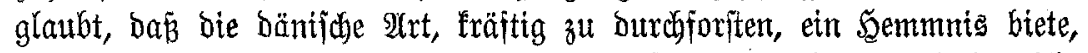

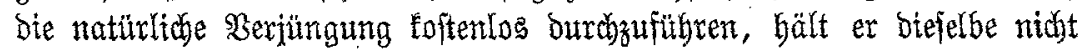
für uns geeignet. Wir befämen böhere Erträge, menn wir tojtenlos auf

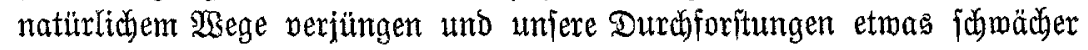
halten. Das jei ber exfte wejentliche \$unft, ber ihm gegen Einfübrung

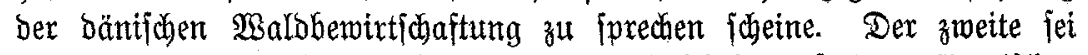

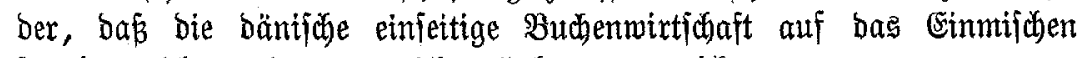
frember, ebler unb ertragreicher Sgolzarten verzichte.

Unier Biel müffe es jein: Erbalten Der nollen Bodenfraft, foftenlos

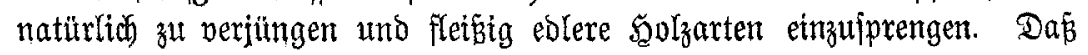




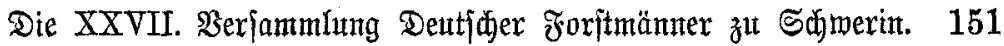

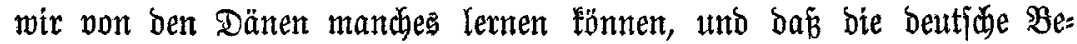
ftandespflege nidyt auf Der Sëhye ber Beit itehe, ift ridtig.

Şierauf fübrte $\mathfrak{B r o f e f f o r ~ D r . ~} \mathfrak{B}$ übler= Tübingen etwa das $\mathfrak{F} \mathfrak{d}=$ gento atts:

Er habe vor zwet Sabren in Stuttgart ein athnliches Thema be= Ganbelt, wobei aber bie öanijhe Durdjpritung nicht bejonders erwälnt worben jei, bas, was man bort mache, fei in einem Deile Deutich=

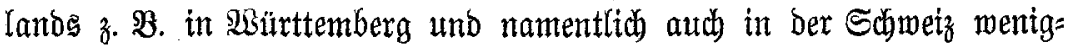

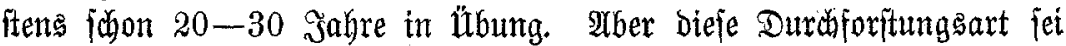

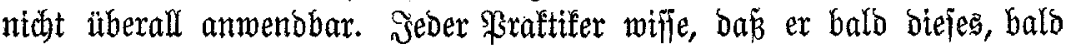
jenes Durdjproftungaverfabren amwende, jedes jei ridutig und er minfle

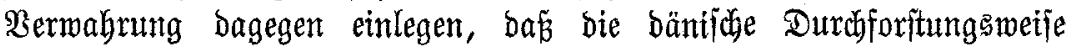

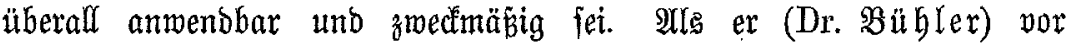

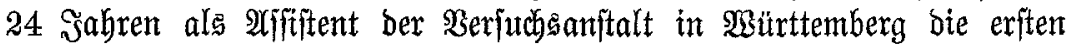
Durdforfortungsyerjuche gemacht hätte, wären bamals fodjon ganz foblecht geformte Stämme bei ber eriften Durchforitung Gerauggenommen woroen. Es jeten brei Durdhforitungsgrade nebenteinandex gelegt worben, in ber

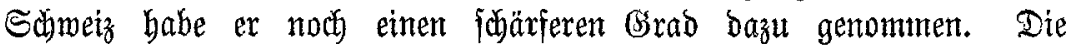

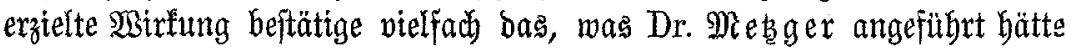

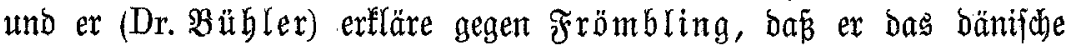

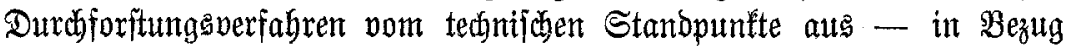
auf bie Entwiďelung ber einzelnen Bäume - jür ridbtig halte, jeiner

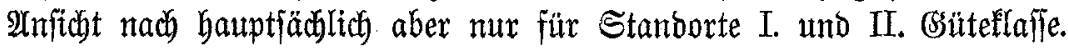

Dr. Mebger ftamme aus bemt (Gebiete, wo bie Durchjoritungararten

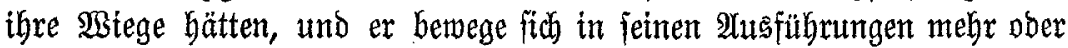

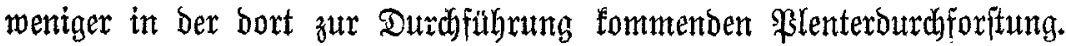

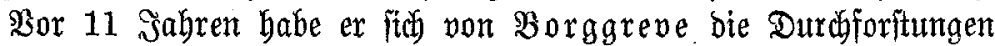
bei Münden zetgen laffen. Es wären bas bamals 60 jäbrige Butchen= beitünbe gewejen, die noch nie burchforftet geweien wären und foldhe müffe nan bod anbers bebanbeln als jene, bie jofon mit bem 20. Sabre

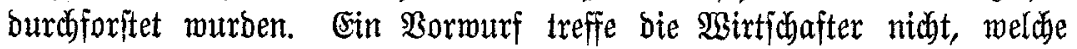

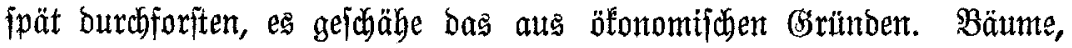
wie fie Mebger aus Beftänden im 60. Săbre gezeichnet babe, gäbe es in frïhburchforfteten $\mathfrak{B e f t a ̈ n d e n ~ u ̈ b e r h a t p t ~ n i d b t ~ m e b r , ~ b i e j e ~ h a u e ~ m a n ~ f a d o n ~ i m ~}$

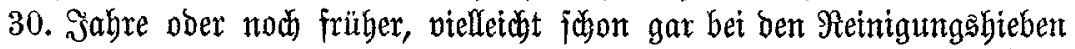

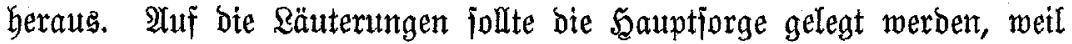
in biejent 2llter ber Sdhluß rajd wieber Kergeftellt werbe, beim Durd $=$ forften babe man bann leidtes Spiel. Dr. Bübler vermifst in ben

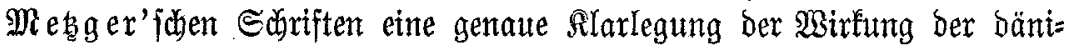
ichen Durchforitungangrt. 
Wenn die Dänen 200 Stämme mit $30 \mathrm{~m}$ Şöhe auf bem 2Ubtriebs: fojlag baben, fo ergäben bieje im ganzen etma $400 \mathrm{fm}$ Derbbolz auf

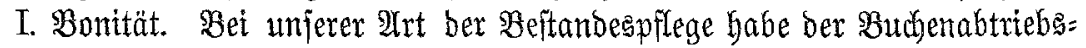
beftand auf I. Bobenflaffe 600, 700 und $800 \mathrm{fm}$ pro Selttar, in Mürt= temberg extitiere fogar ein 130 jähriger $\mathfrak{B u d h e n b e f t a m b ~ n i t ~ n a b e z u ~} 1000 \mathrm{fm}$.

Dann habe Dr. Mebger bie Brufthöbenftärle nur im Durdjiditnitt angegeben, für Dänemart 50 , in Deutidhlant $30 \mathrm{~cm}$. Sin ben $30 \mathrm{~cm}$ ftarten seftänoen, hätten wir aber aud Stämme won 60 and $70 \mathrm{~cm}$

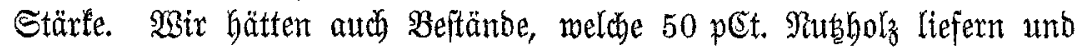
bieje jeien bei $600 \mathrm{fm}$ Mbtriebertrag bod bodwertiger als die bäritiden mit etwa $400 \mathrm{fm}$ Derbholz.

Dann babe Mebger zu jeinem Bergleid bie 2tbtriebsertraggtafeln von Dänemarf bemubst, er (B̈̈bler) wolle nicht fragen, ob bie אon= ftruttion Derfelben ridjtig jei, audi in ben bentfchen Ertragstajeln müpten viele Fragezeichen gemady) werben. Rebner jei es auberdem auth nod)

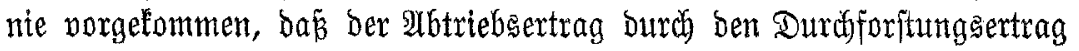

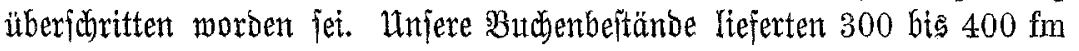
Durdyforitung gerträge.

Dr. B̧iłhler hätte gerne von Dr. Metgger nod gehört: Wate hod

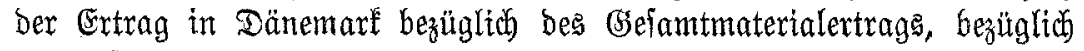
bes gejamten rohen Geloertrags und bezüglich Des reinen Sseldertrags jei. Bielleidgt bole Dr. Megger bas gelegentlidy nach unb erit bann, wem wit flar feien, fönnten wir ein 1 trteil fällen. Bon șntereffe wäre es auch, zut wiffen, mit weldyem allter in Dänemart bie Durdfforftumg in Ungriff genommen würbe, in Stadtwald von 3ürid werde bereits in 12. Şabre bie erfte Durchforitung gefübrt. Sin lebhaftes Bravo beftätigte ben Dante ber : Berjammlung.

Frorftmeifter Dr. Martin (Ebersmalbe) ftimmt in vielen $B e=$

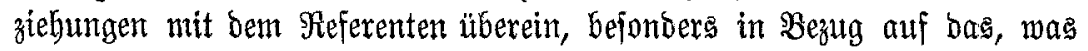
ex betreffe ber Safafthöhe uno ber sronenbiloung gejagt habe, ex fönne aber nicht beipflicten in Bezug auf bas, was Dr. Mebger

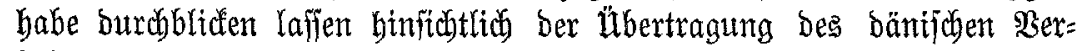

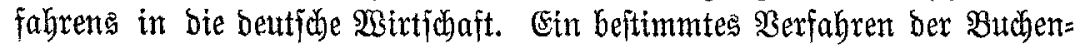
beítandespflege gäbe es in Dänemarf nidyt; bas, was wir barüber gehört bätten, bez̧iehe fict mur auf fleite Wirtichaftebezinfe mit günftigen $\mathfrak{B} e r=$ Gältniffen. SBie $B$ übler, fo mürbe aud er jebenjalls zuritd dyaltend fein in ber Beantwortung ber vorliegenden Frage. Man föme ja in mandjent Dingen allgemetne $\mathfrak{B}$ irtidjafterregeln auffitlen, aber bie Beftandespflege jei bod) immer tn etnent gemiffent Grabe von ben b̈rtlichen Berbültniffen

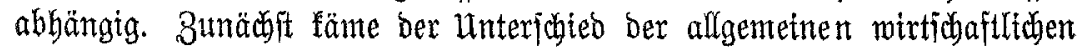


und Rulturverhältniffe, bann ber Buftand bes Einzelbeftandes, bie Ģe= ichidite besfelben in Betract, je nach ber Beftanbesbegründung, nach ben

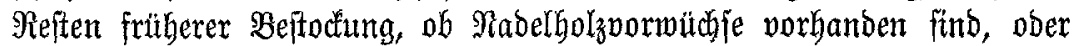
Stodauşfd)läge u. bergl. m.

Dann täme das Mirtichaftşżel in Betracht. Şn Dänemart jei

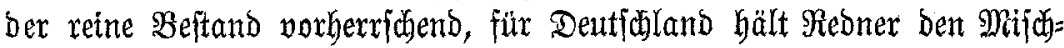

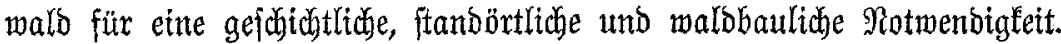
Eingebend auj bie wejentlichen Eigentümlichleiten bes bänifichen Durdforftungaverfahrens bemertt Reoner, ba rittifbften Eigentümlidfeiten besfelben, wie früber Beginn und itarke

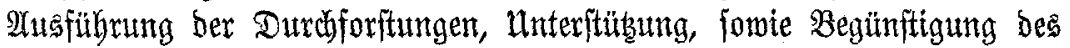
SBefferen unb Erbaltung bes Unterftandes, boch aud in unjerer beutifhen Foritwirtidyaft angemanot jeien, und zwar zunädjft in ben Rehren unjerer gropen Mämer uno in Dex \$raris. Neben Cotta hätten Sartig uno Rarl Sever bie Durdforitungefrage eingehenb bebandelt und bejonders

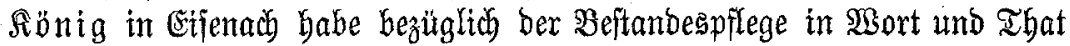
viel (Sutes geleiffet.

Reoner glaubt, baj von Der boppelten Etage nur in bejcheiberem Mape Gebraud gemady merben tömte, bejonberen Wert bätte fie für Den Mifidwals; vor Serallgemeinerung aber mïfife man fich büter.

Man jage, bie deutjo Praris hinfe der Theorie nad, uno bas wir bas nidjt ausführten, was leb̧tere molle. Das bänge im gemiffen

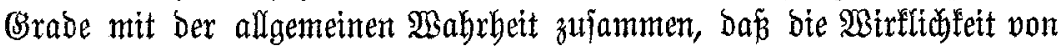
Dem Soale immer entfernt ift. Er (Dr. Martin) glaube bejtätigen zut bürfen, ba

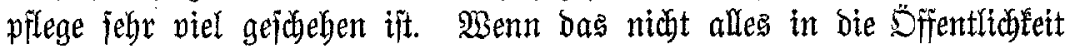
bringe, jo liege Das Daran, da ja gerabe biejenigen, welche fith am meiften ber Pfflege bingeben, nidyts in bie 3eitjuriften idreiben.

SBent man ber allgenteinen Forberung, man müffie viel reijen, um veridhiedene SBirtichaften fennen zu lernen, nachlomme, Dann gelange man

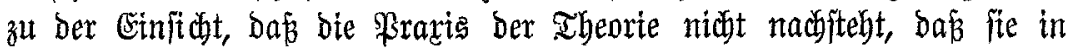
vieler $\Re$ ez̧ieg ung beffer ift als bie Iheorie uno beffer als fie jein würoe, wenn man bas ausländifhe serfahren bei uns einführte.

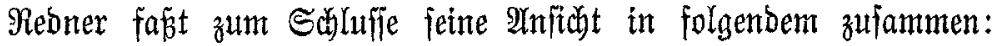

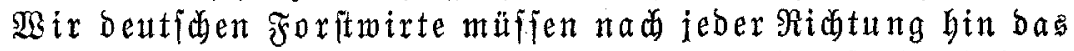
3eug haben, die Forftwirtichaft und oie Forftwifienjaft fort zubilden, wir jollen ung vor bem Generalifieren in ber $B$ e: ftandespflege büten, besgletuden vor ber unmittelbaren $\Re a d b=$ ahmung frember Sirtichaftsonridgriften. 


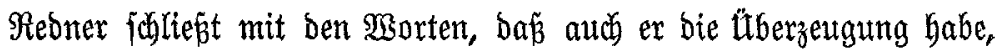
baß man von ben Dänen lernen fönne, und dáp ex felbít zum weiteren Studium nach Dänemarf gehen würbe. (Bravo.)

Frofeffor Dr. von Rorey (Tübingen) würde nidyt geiprochen haben, wenn nicht Dr. Mebger auch der forftlichen Berjuctseanitalten gebacht bätte.

Benn Megher unter III. frage, ob bie bänifbe Durchforfungs= weife in Deutichland bereits atumentung gefunden babe, jo tönne er mur

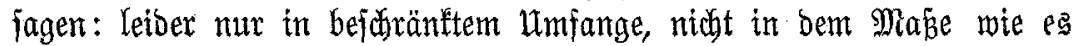
wünjhensmert gewejen wäre. Mian hätte bei uns bisher nibyt gemug nad) bem einzelnen Stamme geieben. Man tönne gar nicht frilgzeitig gemug beginnen mit ben Durbjforitungen, mit Redgt bätte Dberföriter

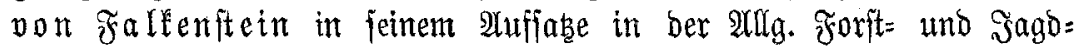
zeitung auf bie Bibtigfeit ber Durbreiferung hingemiejent. Die ribtige

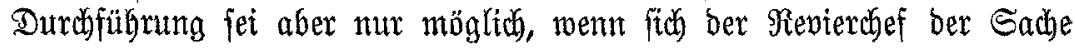
gehörig annähme uno bazu gebörten Hetne Dberföritereien.

Die forftliche Serjuchsanjtalt bätte an Iage zuvor jebr ausgiebig über bie Ermeiterumg bes Arbettsplanes beraten. Es folle in ber $B_{11}=$ funft jibon in ber Sugeno auf ben bejten Stamm gewirtfodaftet und einer

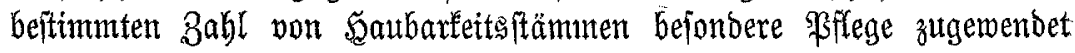
werben.

Eandesforitrat Dr. Bertog hat in Dänemarł mandi Schönes ge= feben, nur fei es ibm vielfach aufgefallen, dap bei ben eriten Durch)= forftungen viel zu fitar in ben Unterftand eingegriffen werbe, wodurch bie Uthreinheit leide. Es werbe nadi jeinen Erfabrungen in ber beut=

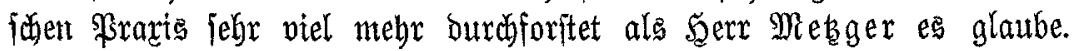

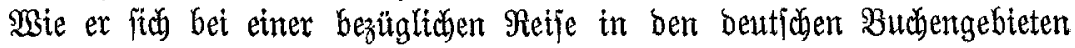
felffit überzeugt habe, wirtoen haberall ba, wo ber Şolzabface möglich ift, Die Durchforitungen gründlid geführt und babei aud bas Beffere bes

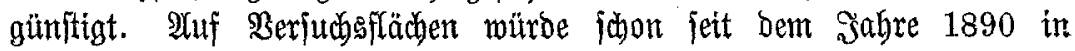
Sreuken fo butchforitet wie in Dänemart.

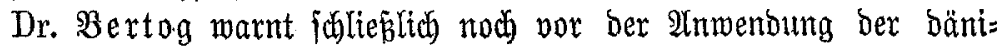
fich Ertragstafeln, bei Deren Seritelling von ber Stammathl aus= gegangen worben jei, und das jet unficter. A2tuch Prof. Dppermann

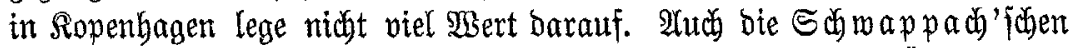
Ertraggtajeln würben in Raufe ber nädfften 10 Jah erfabren.

Forftmeifter Eufig in Stoberau hat jechs Sabre lang bie Dber= föriterei Sonderburg auf ber șinjel âljen permaltet. Es jei bas ein Buthenreviex, beffen Boben= und Beftandesverbältniffe viele äthnlicbleit mit ben bänifben :Berbältnifjen babe. Diefe Berbältniffe feien aber ganz. 


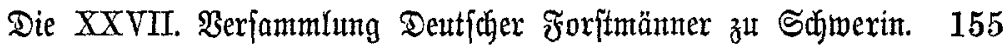

andere mie bei uns im sinnenlanbe, bie man nidht in bie Rarallele ftellen bürfe. Die Schlüffe Me

Das Wirtichaftásiel jei in Dänemarf ein volfitändig anderes wie in Deutjolatand.

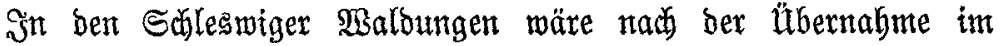
Sabre 1864 bas Nubholzprozent nux 4 gewejen und bennoch bätte ber

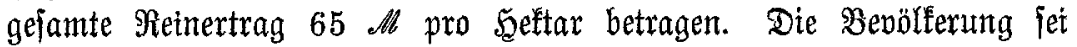
wohlyabeno, Sohlenbrand bätte man nidbt befeffen unb bie Suchenjobeiter

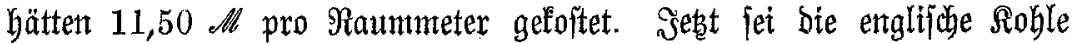
eingeführt, gleitazeitig wären bie Brennbolzpreife gejunten, man müffe

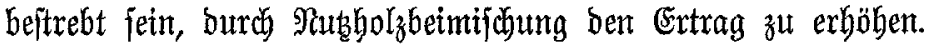

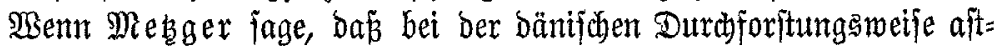
reine Stämme von $15 \mathrm{~m}$ Şöhe erzogen wütoen, fo jei bas für eine

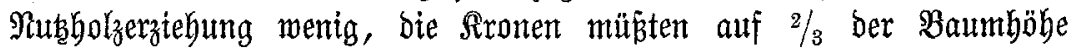

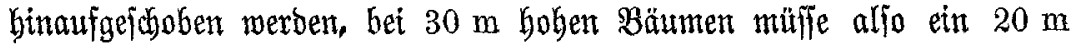
langer ajtreiner Sajaft vorbanben jein.

Die Schlüffje Mebger's bürfen ntudt überall bin übertragen merben.

3um Sdblü ergreift Ranbforitmeifter Dr. Dandelmann bą Wort

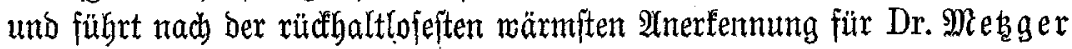
ungefähr bas ærolgende aus:

(Ex jei nach Dänemarł gegangen und nady bem \$lane Mebsger's

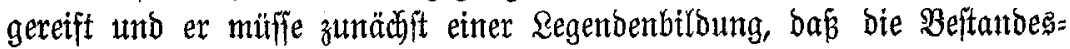

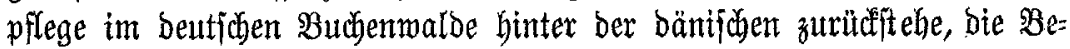
rectitigung abjobneiden.

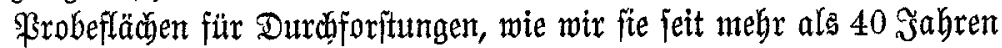
haben, exiftieren bort jo gut wie gar nidjt. Es find einige wenige ba, aber bieje find ntht ausreidhent, um bie groß̉e Frage über ben Erfolg Der SBeftandesppllege zu ergrünoen.

Die Dppermanntifjen Ertragstafeln jeien unzulänglich. Da bieje nicft genügen, um ein $\mathfrak{B i l d}$ von ben Errolgen zu geben, habe er ben

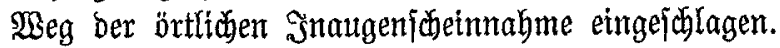

Son ben jüngiten Beftänden werbe geläuttert wie bei itns, ein Unter=

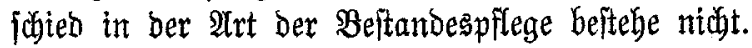

In einem 28 fährigen geringen Stangenholzbeftand wax bereits

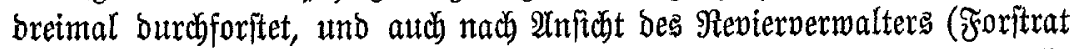

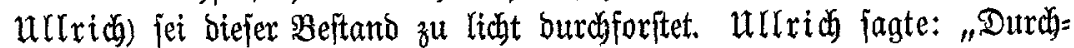
foritungagrad und Beit müifen fich auggleidgen. Şft zu ftarf burchforitet,

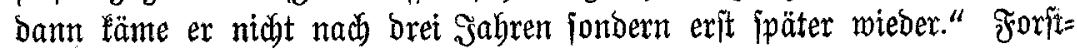
rat Ullrich mollte aljo mäßsig burchforften. 
Şm geringen Stangentyolz fönne von einem Ertennen ber Şatpt= bäume noch nicbt bie Rebe jein.

§m ftarken Stangenfolz merbe ber gute Stamm erfennbar, man milfije beginten, benlelben zat begünitigen.

Beim geringen $\mathfrak{B}$ aumbolz jeien bie ßertitämme fohon in groper

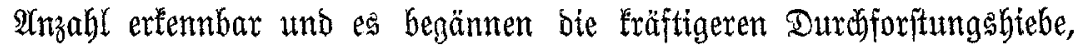
ourdf weldye bie Rronenverbretterung hervorgenufen würbe. Ulber autch

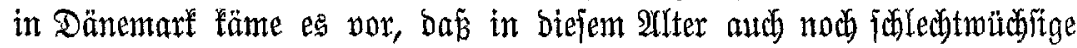
Stämme vorbanben feien. Erft von ba an bis zum ftarfen Baumbolz entfteht ber mejentlibje Itnteribied Durd Rronenverbreiterung und Stamm= zahlverminderung.

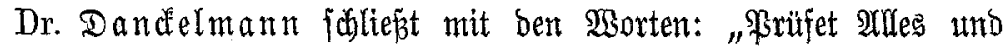
mählet bas Befte."

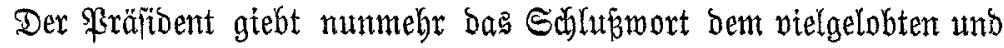
vielangegriffenen Dr. Megger.

Diejer erflärt: Wegen ber Rürze ber ßett fei es ifm nicht möglich, auf all bie an ihn gerichteten Fragen einzugeben, er wolle fich mur auf

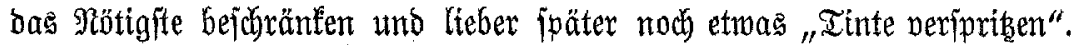

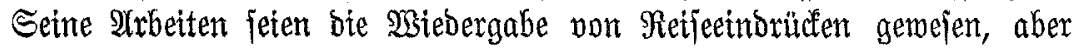

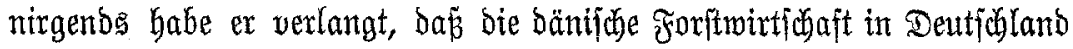
fofort eingefuilght werben folle.

8ut bem vom Forftmeifter Frömbling Gefagten, bemerft ex, dans

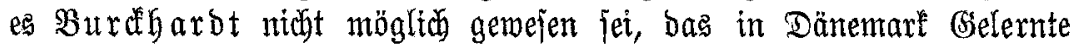

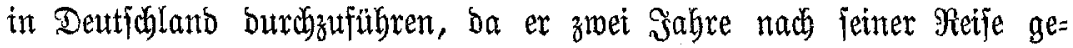
ftorben fei.

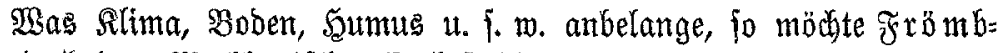

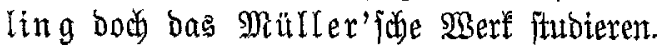

Frömbling fei Spezialijt auf bem B̈ebiete ber ßuthenverjüngung,

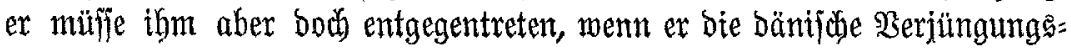

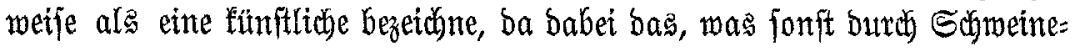
eintrieb bezmedt morben jei, bort burbih Majoinen verurjact weroe. Sold' ein Berfahren bürfe man nidbt vermerfen, fonft bürfte $\mathfrak{F}$ römb= ling audf fein Brot mehr effen, weil bie Bäcterjungen ben Teig Ineten und nicht mehr mit Füzen treten. Der ßooben jet in Dänentarf nur zut geringem Teile (Seeland) fo gitnitig wie in ber Sireibeformation in Fommern.

Prof. 3 übler bätte Mittefling verlangt über ben Beitpunft bes 2lnfangs ber Durdbforftungen in Dänemarf. Es jei barüber bort viel bebattiext morben, in allgemeinen heí̉e es, man föme nidbt früh gentg anfangen, bie Sheinigungen müften der ßerjüngung auf ben Fłnke folgen, 


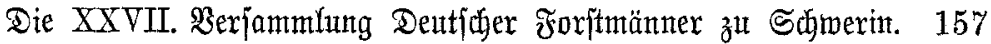

bie eigentliche Durchforftung begänne etwa mit bem 25. Sabre. Das,

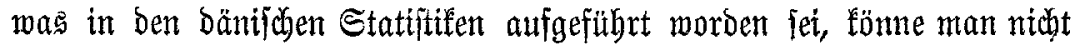
gut mit unjeren Ergebnififen vergletwen, benn bei uns wanbere mandes

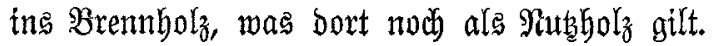

Dem Dr. Martin wirb furz erwibert, man jolle nur bas Bejte be= balten.

2luf Dr. Bertog's Worte fönne er (Meghger) mur entgegnen, es babe ihm nichts ferner gelegen, als bie beutiche Seitandespflege ichlecht zut machen; unt etwas vergleichen zu mollen, müffe man die 2 aabrheit

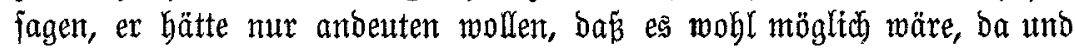
bort vorwärts zut gehen.

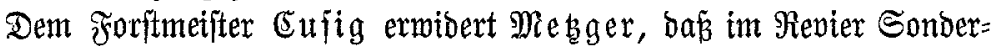
butrg fehr alte Beftände vorbanben jeien, wie fie in Dänemart überbattpt nicht erzogen mürben. Ere fänne bann nicht zuftimmen, wenn $\mathfrak{E} u f i g$

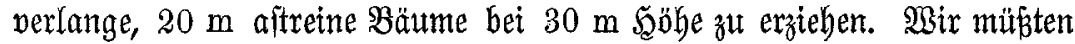
bie Durbmeffer pflegen und nidbt bie Ränge, wie bies audd bie neutiten

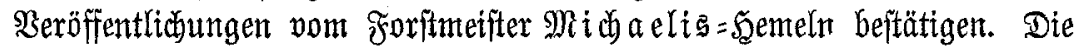

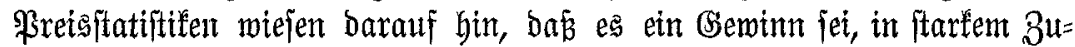

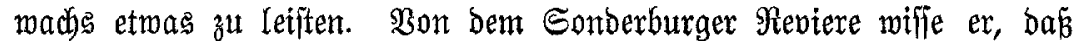

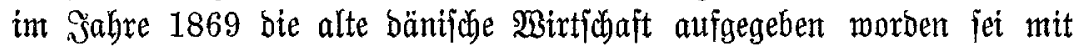

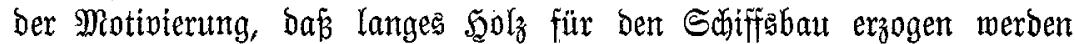

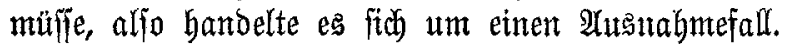

Das $20 b$ bes Eandforitmeifters Dr. Dandelmann verbiene er $(\mathfrak{M e b g e r})$ wohl nicht gants. Es bätte ihm ferne gelegen, die beutjobe

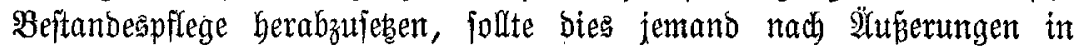

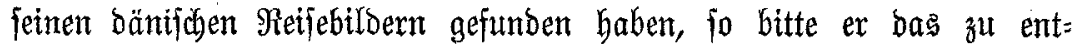
johuldigen. Es fönnte wohl gejohehen jein, im Eifer eine Iendenzidgrift

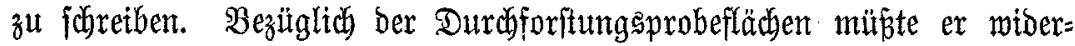

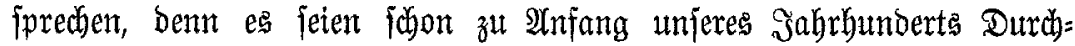
forftungeflächen jtammmetje numeriert morden, und auf denfelben bätten

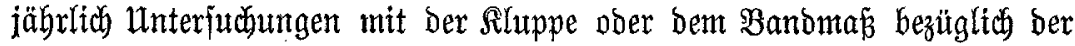
Durdamefferzunahme ftattgefunden. Das jeten bie Grandlagen für bas Werf Deg gropen $\Re$ eventlow gewefen. 2luch für bie Ertragstafeln jeien berühmte Froritmathematifer thätig gewefen.

Der Fräfibent, Dberforiftrat Dr. Fär rit, bält eine abftimmung für augaeidlofjen und faß̉t bas Borgetragene in folgender $\mathfrak{B e i j e ~ z u j a m m e n : ~}$

Dr. Mebger habe fich burdh bie bänifichen Reifebriefe ein ganz ent=

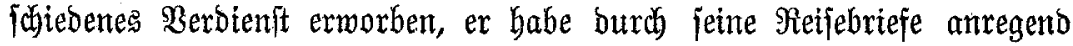
gewirft, es jei aus benjelben eine ganze Ritteratur herausgewadjfen. Dhne Wirtung merbe jeine ânregung nidbt bleiben. IUllein ex jet in mandjen 


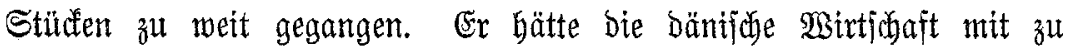
rofigen, uno bie beutiche mit zu bunf̌len Gläjern angejehen. Er bätte

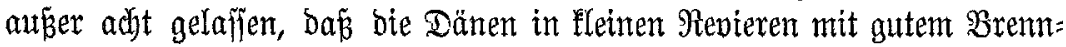
bolzabjate wirtichaften. Şn unferen gropen Revieren wie z. B. im Speffart fei es unmöglich, fionon im zwanzigiten Sabre Durdjforitungen zu fübren, bie Berechtigungen und bie hohen Rofiten ließenen bas nicht zu. Unmendbar jet bas, was Mebgen jage, in vielen Fällen nictst, bagegen aber an= regend und bafür herzliduen Dant.

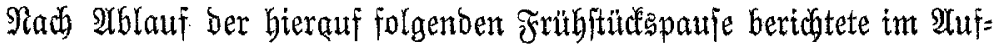

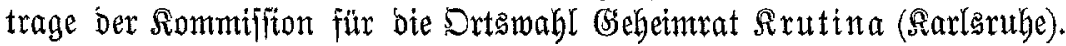

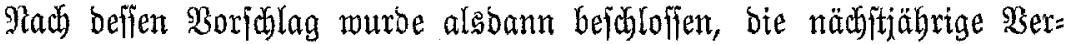
jammlung in Wiesbaben ober, wenn es bort nidjt möglich jei, in Frant= furt a. M. abzubalten. Für 1901 wirs Münberg in 2 dusftidt genommen.

(Fortjesitttg folgt.)

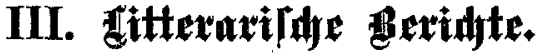

গr. 18.

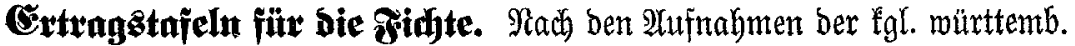
forftr. Berfuctsitation bearbettet und berauggegeben von Dr. Tuisfo

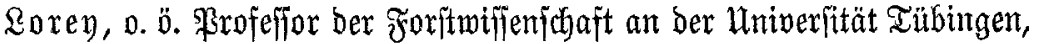

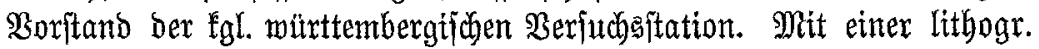

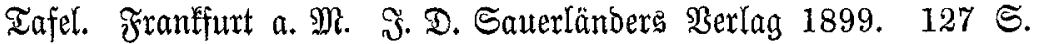
Wiederum liegt eine äntherit intereffinte 2 rbeit soreys (nad) jeiner

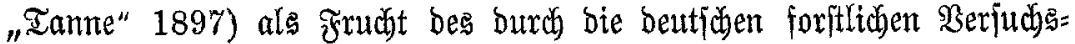
anftalten planmä̈fig geitalteten Borgebens bet ber $\mathfrak{U n t e r j u c h u n g ~ b e r ~}$ Mud mehr ither bie wertvollen Fejultate ber württembergijiben Berjuthe in

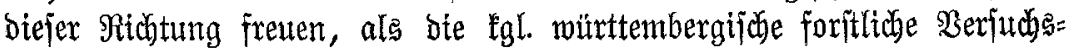
Ftation unter Der Reitung bes veremigten \$rofejfors Dr. v. $\mathfrak{B a u r}$ bie

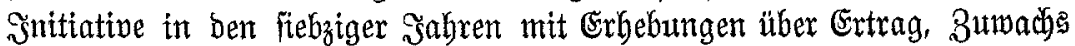
und Form ber Fithte ergriffen hatte.

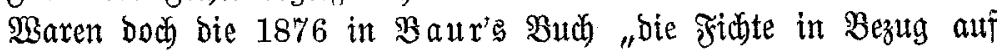
Srtrag, Buwadse und Form" enthaltenen Fichtenertragstafeln bie erften Ertragstafeln überhaupt, weldhe im Bereidhe Des Bereins beuticter forit= licher Berjuchasanitalten zur SSeröffentlichung Famen.

Das jebige reibhaltige Frobeflächenmaterial, ingbejondere bie teil= meije zunt fünftenmale wieberbolten 9 unjnabmen derjelben $B$ ejtände er=

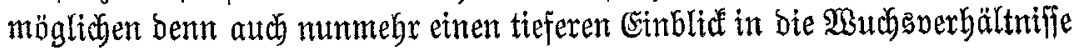

